\title{
Value of family history in identifying women at risk of venous thromboembolism during oral contraception: observational study
}

\author{
Benilde Cosmi, Cristina Legnani, Francesco Bernardi, Sergio Coccheri, Gualtiero Palareti
}

Cardiovascular

Department,

Division of

Angiology, Unità

Ricerca Clinica sulla

Trombofilia "M

Golinelli”,

University Hospital,

S Orsola-Malpighi,

40138, Bologna,

Italy

Benilde Cosmi

lecturer

Cristina Legnani

researcher

Sergio Coccheri

professor of

cardiovascular

medicine

Gualtiero Palareti

consultant in

thrombosis and

haemostasis

Centro di Studi

Biochimici del

Genoma Umano,

Department of

Biochemistry and

Molecular Biology,

University of

Ferrara, Italy

Francesco Bernardi

professor of

biochemistry

Correspondence to: B Cosmi bcosmi@

med.unibo.it

BMJ 2001;322:1024-5

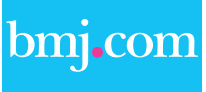

The questionnaire is available on the BMJ's website
Common inherited thrombophilic defects such as factor V Leiden and G20120A mutation of the prothrombin gene interact synergistically with oral contraceptives to increase the risk of venous thromboembolism. ${ }^{12}$ The best approach to identify women at higher risk of venous thromboembolism before taking oral contraceptives is controversial. Universal screening is not cost effective because 8000 women need to be screened for factor $\mathrm{V}$ Leiden to detect 400 mutations and prevent one episode of venous thromboembolism. ${ }^{1}$ Many authors recommend selective screening in women with a personal or family history of venous thromboembolism. ${ }^{1}$ However, the effectiveness of this approach has not been proved. The aim of our study was to evaluate the sensitivity and positive predictive value of a family history of venous thromboembolism for identifying common thrombophilic defects in women without thrombosis before taking oral contraceptives.

\section{Participants, methods, and results}

We prospectively evaluated a cohort of women (age range 15-49 years) consecutively referred to our thrombophilia unit by gynaecologists at family planning clinics in Bologna, Italy, between 1998 and 2000. The gynaecologists had established that the women were eligible to take oral contraceptives and had no history of venous thromboembolism. Before the women were screened, experienced investigators administered a modified structured questionnaire ${ }^{3}$ that was designed and validated to evaluate both personal and family history (first degree $=$ parents and siblings, second degree $=$ grandparents, aunts, uncles, and cousins) of venous thromboembolism (see $B M J$ s website for details). We considered family history positive if a thromboembolism was reported in any first or second degree relatives.

Thrombophilia screening was conducted as previously described. ${ }^{4}$ Prothrombin activity was measured by chromogenic assay ${ }^{5}$ and lupus anticoagulant by LA-test and LA-check assays (Organon Teknika, Rome, Italy). If prothrombin activity was confirmed to be above $1.10 \mathrm{U} / \mathrm{ml}$, we analysed the DNA for the G20120A mutation according to the method of Poort et al. ${ }^{5}$ The tests were performed by staff blind to the results of the questionnaire.

We calculated sensitivity and positive predictive values according to standard methods. The $95 \%$ confidence intervals for proportions were calculated by an approximate method, and we used the $\chi^{2}$ test when appropriate. A two sided probability value $<0.05$ was considered significant. All data were analysed with the statistical package SOLO ( BMDP, Los Angeles).

We evaluated 324 women (mean age 34 years) who had a negative personal history for venous thromboembolism confirmed by our questionnaire. Thirty four women reported a positive family history $(10 \%, 95 \%$ confidence interval $7 \%$ to $14 \%$ ), of whom two were heterozygous for factor $\mathrm{V}$ Leiden and one had protein $\mathrm{S}$ deficiency. Thrombophilic defects were identified in 19 women $(6 \%, 3 \%$ to $8 \%)$, only three of whom had a positive family history. Among the 290 women with a negative family history, thrombophilic defects were detected in $16(6 \%, 3 \%$ to $8 \%)$; eight were heterozygous for factor V Leiden and eight were heterozygous for the G20120A mutation.

The table shows the sensitivity and positive predictive value of family history for identifying thrombophilic defects. The proportion of women with thrombophilia was similar among those with a positive history and those with a negative history of venous thromboembolism when first and second degree family history was considered $(9 \%(3 / 34)$ v 5\% (16/290), $\mathrm{P}=0.44$ ) and when only first degree family history was considered $(8 \%(2 / 26) v 6 \%(17 / 298), \mathrm{P}=0.68)$.

\section{Comment}

Family history of venous thromboembolism has unsatisfactory sensitivity and positive predictive value for identifying carriers of common thrombophilic defects before taking oral contraceptives. A policy of selective screening may therefore miss a substantial number of women at increased risk of thromboembolism when taking oral contraceptives.

We thank the gynaecologists at Bologna family planning clinics who referred women for screening.

Contributors: $\mathrm{BC}$ was involved in the conception and design of the study and drafting the article. GP was involved in the con-

Sensitivity and positive predictive values of family history as a predictor of thrombophilic defects in 324 women with no personal history of venous thromboembolism

\begin{tabular}{|c|c|c|c|c|c|c|}
\hline \multirow[b]{2}{*}{ Family history } & \multicolumn{2}{|c|}{ All defects } & \multicolumn{2}{|c|}{ Factor V Leiden } & \multicolumn{2}{|c|}{ G20120A } \\
\hline & No (\%) & $95 \% \mathrm{Cl}$ & No $(\%)$ & $95 \% \mathrm{CI}$ & No (\%) & $95 \% \mathrm{Cl}$ \\
\hline \multicolumn{7}{|l|}{ First and second degree } \\
\hline Sensitivity & $3 / 19(16)$ & 0.0 to 32 & $2 / 10(20)$ & 0.0 to 45 & $0 / 8$ & - \\
\hline Postive predictive value & $3 / 34(9)$ & 0.0 to 18.3 & $2 / 34(6)$ & 0.0 to 14 & $0 / 34$ & - \\
\hline \multicolumn{7}{|l|}{ First degree only } \\
\hline Sensitivity & $2 / 19(11)$ & 0 to 24.7 & $1 / 10(10)$ & 0 to 28 & $0 / 8$ & - \\
\hline Postive predictive value & $2 / 26(8)$ & 0 to 18 & $1 / 26(4)$ & 0 to 11.2 & $0 / 26$ & - \\
\hline
\end{tabular}


ception and design of the study and critical revision of the article and is the paper's guarantor. CL and SG analysed and interpreted the data and helped revise the article. All authors approved the final draft.

Funding: This project was supported by a grant from the University of Bologna.

Competing interests: None declared.

1 Vandenbroucke JP, van der Meer FJM, Helmerhorst FM, Rosendaal FR. Factor V Leiden: should we screen oral contraceptive users and pregnant women? BMJ 1996;313:1127-30.

2 Martinelli I, Taioli E, Bucciarelli P, Akvahan S, Mannucci PM. Interaction between the G20120A mutation of the prothrombin gene and oral con- traceptive use in deep vein thrombosis. Arterioscler Thromb Vasc Biol 1999;19:700-3

3 Frezzato M, Tosetto A, Rodeghiero F. Validated questionnaire for the identification of previous personal or familial venous thromboembolism. Am J Epidemiol 1996;143:1257-65.

4 Palareti G, Legnani C, Frascaro M, Flamigni C, Gammi L, Gola G, et al Screening of activated protein $\mathrm{C}$ resistance before oral contraceptive treatment: a pilot study. Contraception 1999;59:293-9.

5 Poort SR, Rosendaal FR, Reitsma PH, Bertina RM. A common genetic variation in the 3 '-untranslated region of the prothrombin gene is associated with elevated plasma prothrombin levels and an increase in venous thrombosis. Blood 1996;88:3698-703.

(Accepted 19 December 2000)

\title{
Gestational impaired glucose tolerance does not increase perinatal mortality in a developing country: cohort study
}

\author{
Shenaz Ramtoola, Philip Home, Hassen Damry, Anwar Husnoo, Stephen Ah-Kion
}

The high prevalence of diabetes and impaired glucose tolerance in women of childbearing age in Mauritius provides an opportunity to assess prospectively the risks of adverse outcome in pregnancy of these conditions, whether the conditions are known to be present at conception or diagnosed during pregnancy. ${ }^{1}$ The findings are likely to have consequences for healthcare planning in developing countries.

\section{Participants, methods, and results}

The study hospital (catchment population 250000 ; 4500 deliveries a year) accounts for $22 \%$ of deliveries of babies in Mauritius, hospital deliveries being $80 \%$ of all deliveries on the island. ${ }^{1}$ Cases were registered in 1993-6 at a joint obstetric and medical service for diabetes, and were also found by monitoring admissions to the obstetric wards, and by monitoring all requests for obstetric oral glucose tolerance tests. Data were collected from the mother and from hospital and national records. Diabetes and impaired glucose tolerance were diagnosed using the 1985 WHO criteria. ${ }^{2}$ Outcomes were assessed as miscarriage ( $<28$ weeks), stillbirth, live birth, or neonatal death ( $<1$ week). Neonatal data were obtained from neonatal records, and background information was obtained from national statistics and routinely collected hospital obstetric data. Standard statistical tests were used for analysis of categorical and continuous data.

A total of 294 glucose intolerant pregnancies were registered in 270 women with diabetes or impaired glucose tolerance (mean age 31; SD 6 years). Of these, 110 cases were of pregestational onset and the remainder were diagnosed during pregnancy ( 86 diabetes, 98 impaired glucose tolerance); nine were lost to follow up and 18 miscarried.

Outcome in the 267 pregnancies resulting in live birth or stillbirth is shown in the table. Perinatal
Dr A G Jeetoo Hospital, Port Louis, Mauritius Shenaz Ramtoola specialist

Hassen Damry specialist Anwar Husnoo specialist Stephen Ah-Kion specialist

Human Diabetes and Metabolism Research Centre, University of Newcastle upon Tyne NE2 4HH

Philip Home professor

Correspondence to: S Ramtoola sramtoola@ cwcom.net

Outcome of pregnancy in Mauritius, 1993-6, according to diagnostic category of glucose intolerance. Values are number (percentage) unless otherwise indicated

\begin{tabular}{|c|c|c|c|c|}
\hline & Pregestational diabetes & Gestational diabetes & $\begin{array}{l}\text { Gestational impaired } \\
\text { glucose tolerance }\end{array}$ & $\begin{array}{l}\text { Background } \\
\text { population }\end{array}$ \\
\hline Perinatal mortality per 1000 births & 124 & 116 & 22 & 26 \\
\hline Relative risk $(95 \% \mathrm{Cl})$ & 4.7 (2.7 to 8.2$)$ & $4.4(2.5$ to 7.9$)$ & $0.8(0.2$ to 3.3$)$ & \\
\hline Stillbirth per 1000 births & 67 & 81 & 11 & 14 \\
\hline Relative risk $(95 \% \mathrm{Cl})$ & $4.8(2.2$ to 10.3$)$ & 5.7 (2.8 to 11.7$)$ & $0.8(0.1$ to 5.4$)$ & \\
\hline Early neonatal mortality per 1000 live births & 60 & 38 & 11 & 12 \\
\hline Relative risk $(95 \% \mathrm{Cl})$ & $4.9(2.1$ to 11.6$)$ & $3.1(1.0$ to 9.4$)$ & $0.9(0.1$ to 6.3$)$ & \\
\hline Mean (SD) birthweight $(\mathrm{g})$ & 3059 (641) & $3293(714)$ & $3083(603)$ & $2953(567)$ \\
\hline $\mathrm{P}$ value ( $v$ background population) & NS & 0.001 & 0.05 & \\
\hline Macrosomia $(\geqslant 4000 \mathrm{~g})$ & $7(8)$ & $14(16)$ & $6(7)$ & $147(3)$ \\
\hline Relative risk $(95 \% \mathrm{Cl})$ & $2.4(1.2$ to 4.9$)$ & $4.9(3.0$ to 8.1$)$ & $2.0(0.9$ to 4.3$)$ & \\
\hline $\mathrm{P}$ value ( $v$ background population) & 0.05 & 0.001 & NS & \\
\hline Mean (SD) gestational age (weeks) & $37.0(2.4)$ & $37.7(2.3)$ & $38.5(1.8)$ & NA \\
\hline $\mathrm{P}$ value ( $\mathrm{v}$ pregestational diabetes/gestational diabetes) & NS & 0.05 & $0.001 / 0.05$ & \\
\hline Prematurity (<37 weeks) & $33(37)$ & $19(22)$ & $10(11)$ & NA \\
\hline $\mathrm{P}$ value ( $v$ pregestational diabetes/gestational diabetes) & NS & 0.05 & $0.001 / 0.05$ & \\
\hline Caesarean section & $51(58)$ & $49(57)$ & $40(43)$ & 16 \\
\hline$P$ value ( $v$ background population) & 0.001 & 0.001 & 0.001 & \\
\hline Hypoglycaemia in infant $(<1.7 \mathrm{mmol} / \mathrm{l})$ & $17(21)$ & $11(14)$ & $4(4)$ & NA \\
\hline $\mathrm{P}$ value ( $v$ gestational impaired glucose tolerance) & 0.001 & 0.05 & NS & \\
\hline Hyperbilirubinaemia in infant & $28(35)$ & $30(39)$ & $19(21)$ & NA \\
\hline $\mathrm{P}$ value ( $\mathrm{v}$ gestational impaired glucose tolerance) & 0.05 & 0.05 & NS & \\
\hline
\end{tabular}

\section{bmj.com}

This article is part of the BMJ's randomised controlled trial of open peer review. Documentation relating to the editorial decision making process is available on the BMJ's website 